\title{
Extraskeletal Ewing sarcoma: Diagnosis, management and prognosis (Review)
}

\author{
ABDALLAH ABBOUD ${ }^{1}$, KARIM MASROUHA ${ }^{2}$, MAELLE SALIBA $^{3}$, RACHID HAIDAR $^{1}$, \\ RAYA SAAB ${ }^{4}$, NABIL KHOURY ${ }^{5}$, AYMAN TAWIL $^{3}$ and SAID SAGHIEH ${ }^{1}$ \\ ${ }^{1}$ Division of Orthopedic Surgery, Department of Surgery, American University of Beirut Medical Center, Beirut 1013, \\ Lebanon; ${ }^{2}$ Division of Orthopedic Oncology, Department of Orthopedic Surgery, NYU Langone Health, New York, \\ NY 10016, USA; Departments of ${ }^{3}$ Pathology and Laboratory Medicine, ${ }^{4}$ Pediatrics and Adolescent Medicine \\ and ${ }^{5}$ Diagnostic Radiology, American University of Beirut Medical Center, Beirut 1013, Lebanon
}

Received April 21, 2020; Accepted February 2, 2021

DOI: $10.3892 / \mathrm{ol} .2021 .12615$

\begin{abstract}
Extraskeletal Ewing sarcoma (EES) is a relatively uncommon primary tumor of the soft tissues, which accounts for 20-30\% of all reported cases of ES. Being uncommon, all members of the ES family tumors are treated following the same general protocol of sarcoma tumors. The present review summarizes the diagnosis, management and prognosis of EES, focusing on the differences between the subtypes of ESS. The clinical features and imaging of EES are also discussed. Magnetic resonance imaging is the modality of choice for diagnostic imaging and local staging, while core-needle biopsy with pathological testing is used to obtain a definitive diagnosis. Although several oncology groups endorse that ES family of tumors should be treated with similar algorithm and protocols, some studies have demonstrated that surgery and radiotherapy may be used as a form of local control. However, further studies are required to conclude the optimum treatment option for EES.
\end{abstract}

\section{Contents}

1. Introduction

2. Epidemiology

Correspondence to: Dr Said Saghieh, Division of Orthopedic Surgery, Department of Surgery, American University of Beirut Medical Center, Phase 1 Building Ghandi Street, Beirut 1013, Lebanon E-mail:ss15@aub.edu.lb

Abbreviations: EES, extraskeletal Ewing sarcoma; ESFT, Ewing sarcoma family of tumors; ESB, Ewing sarcoma of bone; pPNET, peripheral primitive neuroectodermal tumor; US, ultrasonography; $\mathrm{CT}$, computed tomography; MR, magnetic resonance; FDG-PET, fluorodeoxyglucose-positron emission tomography; NCCN, National Comprehensive Cancer Network; CESS, European Cooperative Ewing Sarcoma Studies; EICESS, European Intergroup Cooperative Ewing's Sarcoma Study

Key words: Ewing sarcoma, diagnosis, prognosis, therapy
3. Diagnosis
4. Treatment
5. Prognosis
6. Conclusions

\section{Introduction}

Extraskeletal Ewing sarcoma (EES) is a rare entity that belongs to the ES family of tumors (ESFT), which is a group of small round tumor cells that share a common neural histology and genetic mechanism (1-4). In addition to EES, ESFT includes the classical ES of bone (ESB), which is the second most common primary bone malignancy in the pediatric population, peripheral primitive neuroectodermal tumor (pPNET) and Askin tumor of the chest wall, which is a subtype of pPNET (5). EES was first discovered in 1969 (6), but it remains an elusive pathology in the literature.

Magnetic resonance (MR) and fluorodeoxyglucosepositron emission tomography (FDG-PET) imaging are used for initial diagnosis and detection of metastasis, respectively (7-9). Definitive treatment for localized disease include chemotherapy (10-12) and surgery (13). Radiation therapy is effective in unresectable diseases (14).

The present review discusses the imaging and diagnostic modalities (histology and molecular genetics) used for the initial diagnosis and detection of metastasis in EES. In addition, the present review provides an update on the current treatment protocols (chemotherapy, surgery and radiotherapy) at different stages of the disease and their respective outcomes.

\section{Epidemiology}

The incidence of EES is 0.4 per million, which is 10 times less than that of ESB (1). Its prevalence follows a bimodal distribution, peaking in those who are $<5$ years and $>35$ years (15). Patients with EES tend to be older than those with ESB, and EES is not associated with sex or race unlike ESB (15-17).

EES is a rapidly growing mass that causes localized pain (18). It develops within the soft tissues of any anatomic 
region, but the most common sites include the upper thigh, buttocks, upper arm and shoulders (18). Conversely, metastases are commonly observed in the lungs, bones and bone marrow (19). Thus, the symptoms of EES depend on its primary site, as well as the site of metastases, which are found in $25 \%$ of all cases at presentation (19).

\section{Diagnosis}

Diagnosis and local staging. Imaging plays a central role in the diagnosis, staging, treatment monitoring and surveillance of EES (20). However, the imaging characteristics of EES are non-specific (20-22). EES can be diagnosed via ultrasonography (US), computed tomography (CT) or MR imaging, with each modality having its own specific indications (20).

With US, EES usually appears as a heterogenous mass of low echogenicity with intratumor flow signals on a Doppler study. With CT, EES presents as a large sharply demarcated mass with similar intensity to the surrounding muscles. Post-contrast medium enhancement reveals areas of necrosis, while the surrounding viable contour appears enhanced and heterogeneous (20). Calcification is present in only $10 \%$ of cases, appearing faint and amorphous (20). With MR imaging, EES has low-to-intermediate signal intensity on T1-weighted sequences and displays high signal intensity on T2-weighted images, with variable post-contrast enhancement (Fig. 1) (20-23). MR imaging is performed prior to biopsy to help determine the optimal biopsy site and to avoid the distortion caused by post-biopsy changes (24). This is also recommended for restaging purposes prior to local control, as the tumor may have receded or progressed during neo-adjuvant chemotherapy (7).

MR imaging and CT scans are accurate for local staging of malignant bone and soft-tissue tumors (7). However, MR imaging is used more frequently due to its high detection sensitivity for soft tissue contrast, as well as its ability to avoid radiation exposure from $\mathrm{CT}$ scans (7).

Systemic staging and surveillance. In addition to local staging of the primary tumor, imaging is also used to detect the presence of metastatic disease. CT scans of the chest are superior to conventional radiographs in detecting lung metastasis. Intravenous contrast is not required unless there is hilar, mediastinal or chest wall involvement that may require further delineation of these regions. With chest CT, metastatic legions are typically round, ovoid, sharply demarcated and located in the lung periphery (7). Notably, it is recommended to perform a chest CT prior to biopsy to avoid the stimulation of metastasis due to atelectasis secondary to general anesthesia (7).

Bone scans are also recommended for detection of bone metastasis at presentation. If regions of increased uptake are noted on the scan, radiographs are performed to further confirm the presence of metastasis (7). This may be followed by cross-sectional imaging modalities of these areas if the diagnosis of metastasis is uncertain (7). FDG-PET appears to be superior to bone scans for the detection of bone metastasis in ES $(8,9)$. FDG-PET is also used to assess chemotherapeutic response and detect recurrent disease (7). Gerth et al (25) reported that PET/CT is sensitive (87\%) and specific (97\%) for detecting distant metastasis, with an accuracy of $94 \%$.

Overall, definitive diagnosis is made with a CT-guided or ultrasound-guided core-needle biopsy, as well as pathological examination of the resected surgical specimen (26).

Histology. EES is a soft, multilobulated, gray-yellow tumor, whose diameter rarely exceeds $10 \mathrm{~cm}$ (18). EES can contain cystic, hemorrhagic or necrotic areas; however, calcifications are rare (18). Microscopically, EES appears as monomorphic, small, round blue cells that contain large spherical nuclei, inconspicuous nucleoli and indistinct cytoplasmic borders (27). These cells lack extracellular matrix and have low mitotic activity, albeit necrotic areas are commonly observed (Figs. 2 and 3) (27).

Immunohistochemistry is used in addition to light microscopy to diagnosis EES (18). A spectrum of immunohistochemical markers are used to study EES since no marker is pathognomonic (18). These markers include CD99 antigen, which is a single-chain type-1 glycoprotein that is highly sensitive but not specific, S-100 protein and synaptophysin, both of which are neural markers, and FLI1, which was recently discovered as a DNA-binding transcription factor that is involved in $\mathrm{t}(11 ; 22)$ translocation and has higher specificity than CD99 $(18,28)$.

Molecular genetics. The use of pathology and immunohistochemistry for the diagnosis of EES is sufficient in most cases. However, molecular genetic analysis via reverse transcriptase (RT) PCR or fluorescence in-situ hybridization (FISH) add an additional diagnostic domain that is essential in unusual variants. The two most common chromosomal translocations specific to EES and ESFT are $\mathrm{t}(11 ; 22)(\mathrm{q} 24 ; \mathrm{q} 12)$ and $\mathrm{t}(21 ; 22)$ (q22;q12) (29). Translocation $\mathrm{t}(11 ; 22)(\mathrm{q} 24 ; \mathrm{q} 12)$ is present in $90 \%$ of all cases, which causes a fusion between the FLI gene on 11q24 and the EWSR1 gene on 22q12, creating an EWS/FLI-1 transcript that has the DNA binding domain of FLI-1 instead of the RNA-binding domain of EWS (29). Conversely, translocation $\mathrm{t}(21 ; 22)(\mathrm{q} 22 ; \mathrm{q} 12)$ fuses EWSR1 and ERG, which is another DNA-binding protein (30), creating an oncogenic transcription factor that inhibits apoptosis (30). Less common translocations have also been reported, all of which involve the EWSR1 gene on chromosome 22 (30).

\section{Treatment}

Only a few studies have investigated the optimal treatment options and prognostic factors for EES (13,31-34). Previously, EES was treated using the soft-tissue sarcomas protocol (21); however, the current treatment recommendation by the National Comprehensive Cancer Network (NCCN) is local treatment (surgery and/or radiotherapy) plus chemotherapy $(31,32)$. According to the NCCN and the European Society for Medical Oncology $(31,32)$, all members of the Ewing family can be treated with the same algorithm, although the optimum treatment and natural history of EES remain unknown $(31,32)$. Previous studies have demonstrated the role of surgery in EES compared with skeletal ES, suggesting that wide surgical resection increases the survival rate of patients with EES than those with ESB $(33,34)$. 
A

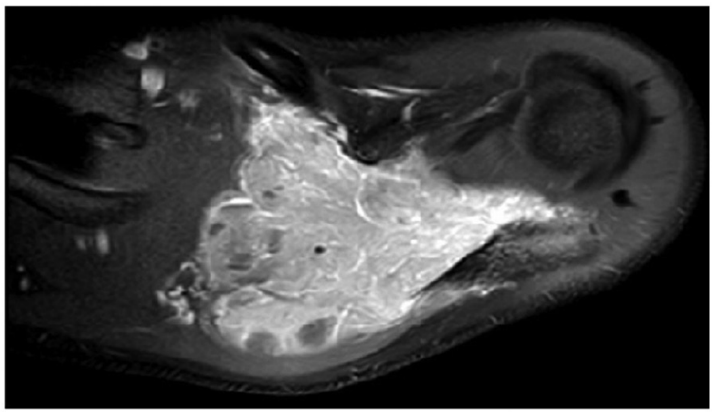

B

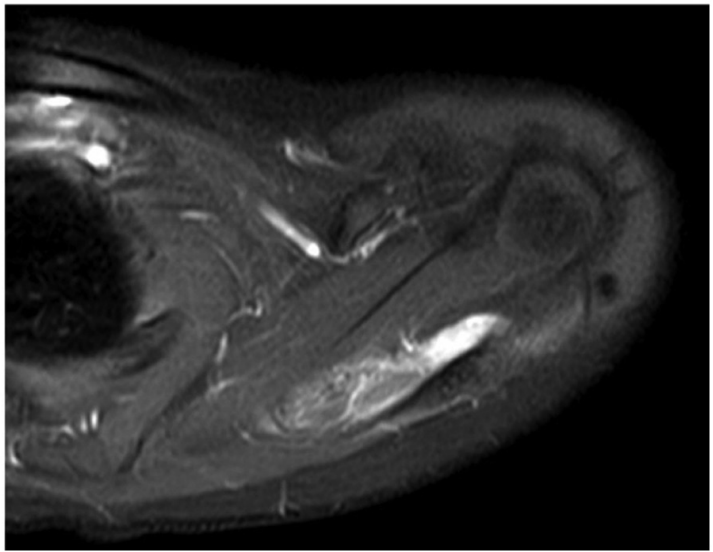

Figure 1. Axial selective suppression of fat gadolinium-based contrast agent magnetic resonance image of the left shoulder of a 16-year-old woman with extraskeletal Ewing sarcoma (A) pre- and (B) post-chemotherapy treatment.

Systemic treatment: Chemotherapy. The use of systemic chemotherapy in the treatment of localized ESFT has increased the 5-year survival rate from 5 to $10 \%$, to $>65 \%$, which is primarily due to the elimination of micrometastases (3). To the best of our knowledge, Rud et al (34) was the first to report on the importance of multiagent chemotherapy in the treatment of patients with EES, demonstrating that the survival rate increased from $28 \%$, before 1970 , to $48 \%$, after 1970 . In addition, Raney et al (10) reported a 10-year survival rate of $61-77 \%$ following multiagent chemotherapy. According to Bacci et al (11), neoadjuvant and adjuvant chemotherapies exhibited comparable results in patients with localized disease. Overall, chemotherapy improves the overall survival rates and decreases the likelihood of recurrence following surgery (12).

The current regimens include alternating vincristinedoxorubicin, cyclophosphamide and ifosfamide-etoposide cycles every 3 weeks (Tables I and II) (35). Womer et al (35) demonstrated that patients who received the same chemotherapy regimen every 2 weeks instead of 3 weeks, known as interval compression, exhibited a better event-free survival rate (73 vs. $65 \%$ ) (36). Although chemotherapy programs are essential and have proven effective, chemotherapy alone without surgery and/or radiotherapy is insufficient as a treatment option (36).

Localized treatment: Surgery and/or radiotherapy. EES is radiosensitive; however, the use of radiotherapy alone for local control has proved less effective over the years. This is due to advancements in surgical techniques for limb salvage, as well as the adverse effects of radiotherapy and the high incidence of local recurrence ( $>30-35 \%)$. Nonetheless, studies
A
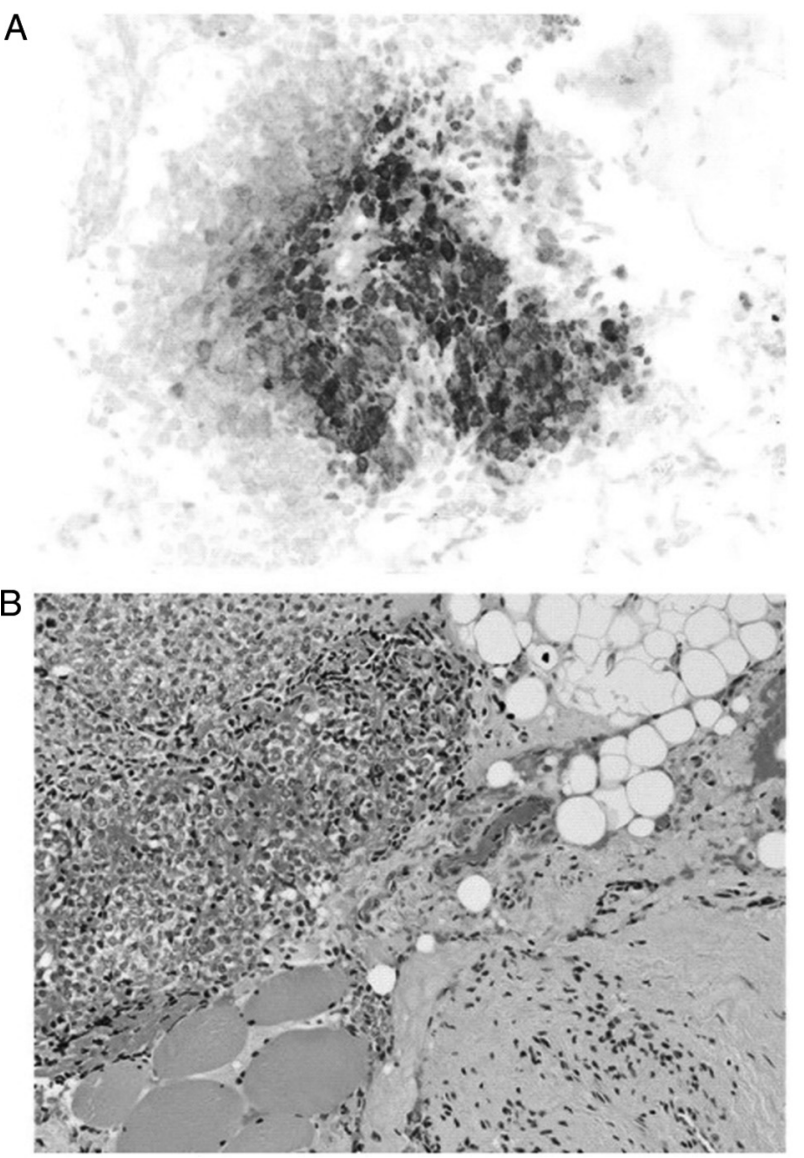

Figure 2. Images of the left shoulder of a 16-year-old woman with extraskeletal Ewing sarcoma. (A) Hematoxylin and eosin staining presents uniform round blue cells infiltrating soft tissue in a random distribution (magnification, x20). (B) NSE in addition to CD99 positivity demonstrated that the tumor cells were positive for NSE (magnification, $\mathrm{x} 20$ ). NSE, neuron specific enolase staining.

comparing surgery with radiotherapy may have overlooked the importance of selection factors dictating local therapy decisions $(4,32)$. Surgery is performed in cases where marginal or wide resection is possible $(32,37)$. Resectable lesions are usually small, peripheral in location and have a good response to induction chemotherapy (36). Conversely, irradiated lesions are often large, central in location and have a poor response to induction chemotherapy (36). The ability to obtain adequate negative margins has the strongest influence on local control of malignancy. Wider margins are required when the response to chemotherapy is not adequate $(4,32)$. When it is not possible to obtain wide margins due to the presence of fixed structures, such as vessels and/or nerves, postoperative radiotherapy can be implemented for better local control $(4,32)$.

The overall 5-year survival rate is better in patients who undergo complete resection, with wide surgical margins compared with suboptimal margins (13). However, if the tumor is not resectable with clear margins (spine or skull) or if surgery would involve vital fixed structures, definitive radiotherapy can be implemented (14,37).

According to the European Cooperative Ewing Sarcoma Studies (CESS) and European Intergroup Cooperative Ewing's Sarcoma Study (EICESS) trials (38), intralesional resection with radiotherapy did not result in a superior local control rate 
Table I. Interval compressed chemotherapy for Ewing sarcoma (35). Induction chemotherapy.

\begin{tabular}{lcc}
\hline Regimen & Drug & Timing \\
\hline A & Vincristine & Weeks 1, 5 and 6 \\
& Doxorubicin & Weeks 3, 7 and 11 \\
B & Filgrastim & Ifosfamide \\
& Etoposide & Filgrastim \\
\hline
\end{tabular}

Table II. Interval compressed chemotherapy for Ewing sarcoma (35). Consolidation therapy.

\begin{tabular}{|c|c|c|c|c|}
\hline Regimen & Drug & Surgery alone & Radiotherapy alone & Surgery and radiotherapy \\
\hline A & $\begin{array}{l}\text { Vincristine } \\
\text { Doxorubicin } \\
\text { Cyclophosphamide } \\
\text { Filgrastim }\end{array}$ & Weeks 15 and 19 & $\begin{array}{l}\text { Weeks } 13 \text { (with the } \\
\text { start of RT) and } 25\end{array}$ & $\begin{array}{l}\text { Weeks } 15 \text { (with the start } \\
\text { of RT) and } 27\end{array}$ \\
\hline B & $\begin{array}{l}\text { Ifosfamide } \\
\text { Etoposide } \\
\text { Filgrastim }\end{array}$ & $\begin{array}{l}\text { Weeks } 17,21,25 \\
\text { and } 29\end{array}$ & $\begin{array}{l}\text { Weeks } 15,19,23 \\
\text { and } 27\end{array}$ & Weeks $17,21,25$ and 29 \\
\hline $\mathrm{C}$ & $\begin{array}{l}\text { Vincristine } \\
\text { Cyclophosphamide } \\
\text { Filgrastim }\end{array}$ & Weeks 23 and 27 & Weeks 17 and 21 & Weeks 19 and 23 \\
\hline
\end{tabular}

RT, radiation therapy.
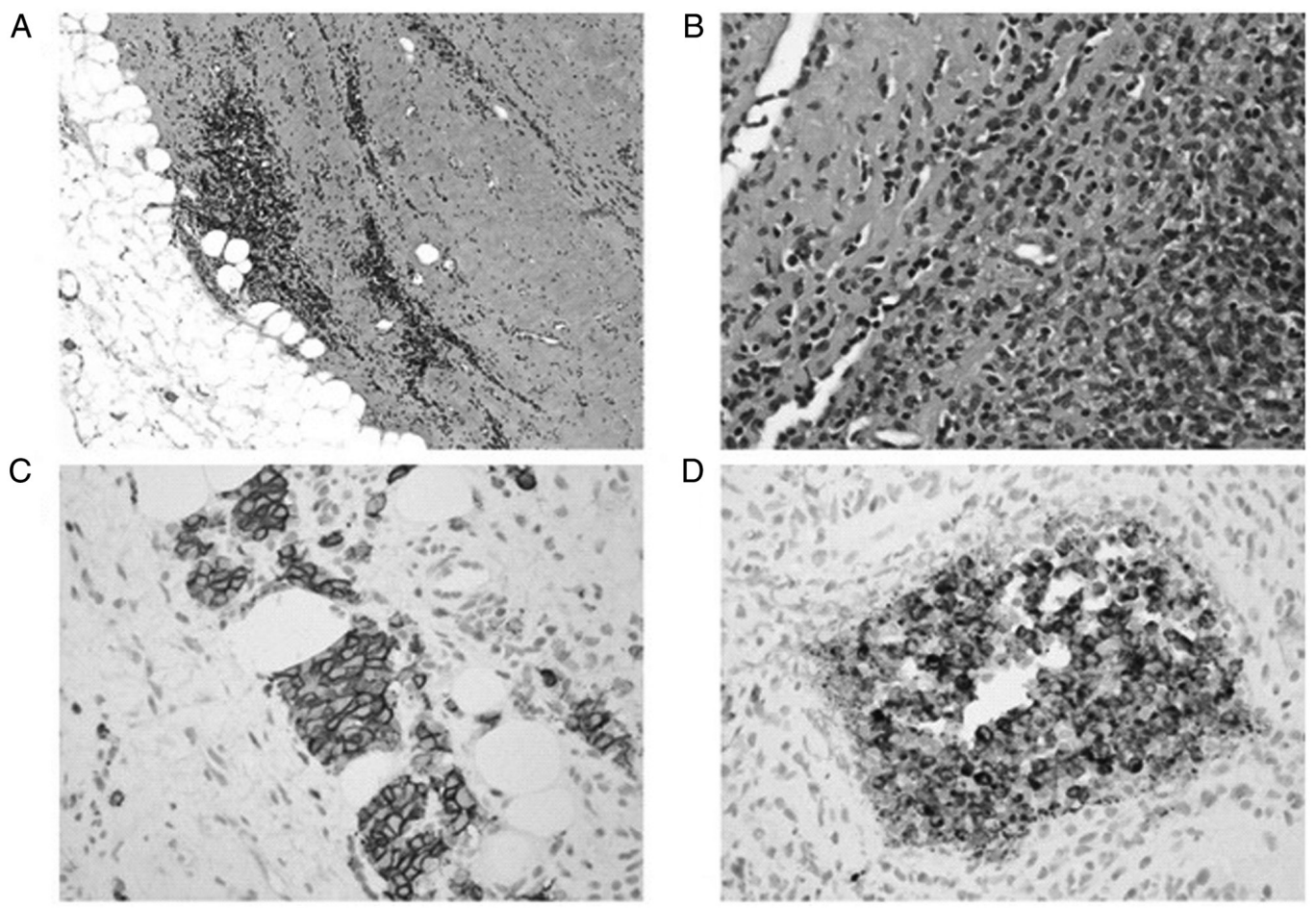

Figure 3. Images of the left distal thigh of a 20-month-old girl with extraskeletal Ewing sarcoma. (A) Hematoxylin and eosin staining of Ewing sarcoma involving fibroadipose tissue and skeletal muscle (magnification, x10). (B) Hematoxylin and eosin staining of tumor cells demonstrated high NC ratio, with indistinct cytoplasmic borders (magnification, x40). (C) Infiltrate demonstrating strong membranous positivity for CD99 (magnification, x40). (D) Positive staining for neural marker synaptophysin (magnification, $\mathrm{x} 40$ ). $\mathrm{NC}$, nuclear-cytoplasmic. 
compared with radiotherapy alone. In such cases, surgery can be avoided in favor of radiotherapy (38). Currently, definitive radiotherapy is only indicated for inoperable lesions, with a recommended dose of 54-55 Gy depending on the involved site $(10,39)$. However, larger tumors may require higher doses $(10,39)$.

Metastatic disease. Metastatic disease or unresectable recurrent disease is treated with the same approach as localized disease but carries a worse prognosis (32). In such cases, chemotherapy is an option, with the limited benefit of extending progression-free survival (23). In patients with lung metastasis, whole lung irradiation has been demonstrated to offer survival benefit (40). Chemotherapy regimens similar to localized disease can be used in such cases but are less effective (32).

\section{Prognosis}

The prognosis of EES is more favorable compared with the skeletal subtype, although factors affecting prognosis seem to be similar in both subtypes $(16,17,41)$. Notably, the 5-year overall survival rate is superior for localized EES compared with localized skeletal ES (15).

Risk factors associated with worse prognosis in EES include older age (26), pelvic involvement (42), high WBC, elevated $\mathrm{LDH}$ and low $\mathrm{Hb}$ at the time of diagnosis $(43,44)$. Intitial tumor size is also a risk factor and is considered a strong prognostic factor in localized disease (26). However, for those treated with neoadjuvant chemotherapy, histological response is regarded as the strongest independent prognostic factor (37). Metastatic disease is a bad prognostic factor, with a 5 -year overall survival rate $<30 \%$ and $<20 \%$ in the case of extrapulmonary involvement (45). The favorable prognositc factors include lesions at the extremity and surgery (46). Notably, recurrent ES, whether localized or metastatic, is almost always fatal (10).

\section{Conclusions}

In the evaluation and diagnosis of EES, while MR imaging is used for local staging, FDG-PET is used to detect metastatic disease. Immunohistochemical analysis, as well as RT PCR and FISH are performed to detect genetic translocations to confirm the diagnosis. Definitive treatment for localized disease include neoadjuvant chemotherapy followed by surgery. Radiation therapy plays a role in unresectable disease or when negative margins are not possible.

\section{Acknowledgements}

Not applicable.

\section{Funding}

No funding was received.

\section{Availability of data and materials}

Not applicable.

\section{Authors' contributions}

AA, KM, MS, RH, RS, NK, AT and SS contributed equally to the preparation of the present study, including the literature review and drafting the initial manuscript. AA and KM confirmed the authenticity of all the raw data. All authors have read and approved the final manuscript.

\section{Ethics approval and consent to participate}

Not applicable.

\section{Patient consent for publication}

Not applicable.

\section{Competing interests}

The authors declare that they have no competing interests.

\section{References}

1. Van den Berg H, Heinen RC, van der Pal HJ and Merks JH: Extra-osseous Ewing sarcoma. Pediatr Hematol Oncol 26: 175-185, 2009.

2. Peabody TD and Attar S (eds): SpringerLink: Orthopaedic Oncology: Primary and metastatic tumors of the skeletal system. In: Cancer Treatment and Research. Cham, Springer International Publishing, Imprint, Springer, Berlin, Germay, pp 203-223, 2014.

3. El Weshi A, Allam A, Ajarim D, Al Dayel F, Pant R, Bazarbashi S and Memon M: Extraskeletal Ewing's sarcoma family of tumours in adults: Analysis of 57 patients from a single institution. Clin Oncol (R Coll Radiol) 22: 374-381, 2010.

4. Carpentieri DF, Qualman SJ, Bowen J, Krausz T, Marchevsky A and Dickman PS; Cancer Committee, College of American Pathologists: Protocol for the examination of specimens from pediatric and adult patients with osseous and extraosseous Ewing sarcoma family of tumors, including peripheral primitive neuroectodermal tumor and Ewing sarcoma. Arch Pathol Lab Med 129: 866-873, 2005.

5. Iwamoto Y: Diagnosis and treatment of Ewing's sarcoma. Jpn J Clin Oncol 37: 79-89, 2007

6. Tefft M, Vawter GF and Mitus A: Paravertebral 'round cell' tumors in children. Radiology 92: 1501-1509, 1969.

7. Meyer JS, Nadel HR, Marina N, Womer RB, Brown KL, Eary JF, Gorlick R, Grier HE, Randall RL, Lawlor ER, et al: Imaging guidelines for children with Ewing sarcoma and osteosarcoma: A report from the children's oncology group bone tumor committee. Pediatr Blood Cancer 51: 163-170, 2008.

8. Franzius C, Sciuk J, Daldrup-Link HE, Jürgens H and Schober O: FDG-PET for detection of osseous metastases from malignant primary bone tumours: Comparison with bone scintigraphy. Eur J Nucl Med 27: 1305-1311, 2000.

9. Völker T, Denecke T, Steffen I, Misch D, Schönberger S, Plotkin M, Ruf J, Furth C, Stöver B, Hautzel H, et al: Positron emission tomography for staging of pediatric sarcoma patients: Results of a prospective multicenter trial. J Clin Oncol 25: 5435-5441, 2007

10. Raney RB, Asmar L, Newton WA Jr, Bagwell C, Breneman JC, Crist W, Gehan EA, Webber B, Wharam M, Wiener ES, et al: Ewing's sarcoma of soft tissues in childhood: A report from the intergroup rhabdomyosarcoma study, 1972 to 1991 . J Clin Oncol 15: 574-582, 1997.

11. Bacci G, Balladelli A, Forni C, Ferrari S, Longhi A, Bacchini P, Alberghini M, Fabbri N, Benassi M, Briccoli A and Picci P: Adjuvant and neoadjuvant chemotherapy for Ewing sarcoma family tumors in patients aged between 40 and 60: Report of 35 cases and comparison of results with 586 younger patients treated with the same protocols in the same years. Cancer 109: 780-786, 2007. 
12. Castex MP, Rubie H, Stevens MC, Escribano CC, de Gauzy JS, Gomez-Brouchet A, Rey A, Delattre O and Oberlin O: Extraosseous localized Ewing tumors: Improved outcome with anthracyclines-the French society of pediatric oncology and international society of pediatric oncology. J Clin Oncol 25: 1176-1182, 2007.

13. Ahmad R, Mayol BR, Davis M and Rougraff BT: Extraskeletal Ewing's sarcoma. Cancer 85: 725-731, 1999.

14. Dunst $\mathrm{J}$ and Schuck A: Role of radiotherapy in Ewing tumors. Pediatr Blood Cancer 42: 465-470, 2004.

15. Applebaum MA, Worch J, Matthay KK, Goldsby R, Neuhaus J, West DC and Dubois SG: Clinical features and outcomes in patients with extraskeletal Ewing sarcoma. Cancer 117: 3027-3032, 2011

16. Lynch AD, Gani F, Meyer CF, Morris CD, Ahuja N and Johnston FM: Extraskeletal versus skeletal Ewing sarcoma in the adult population: Controversies in care. Surg Oncol 27: 373-379, 2018.

17. Cash T, McIlvaine E, Krailo MD, Lessnick SL, Lawlor ER, Laack N, Sorger J, Marina N, Grier HE, Granowetter L, et al: Comparison of clinical features and outcomes in patients with extraskeletal versus skeletal localized Ewing sarcoma: A report from the children's oncology group. Pediatr Blood Cancer 63: 1771-1779, 2016

18. Goldblum J, Folpe A and Weiss S: Enzinger and weiss's soft tissue tumors. 6th edition. Elsevier Health Sciences, 2014.

19. Grier HE: The Ewing family of tumors. Ewing's sarcoma and primitive neuroectodermal tumors. Pediatr Clin North Am 44: 991-1004, 1997.

20. Javery O, Krajewski K, O'Regan K, Kis B, Giardino A, Jagannathan $\mathrm{J}$ and Ramaiya $\mathrm{NH}$ : A to $\mathrm{Z}$ of extraskeletal Ewing sarcoma family of tumors in adults: Imaging features of primary disease, metastatic patterns, and treatment responses. AJR Am J Roentgenol 197: W1015-W1022, 2011.

21. Huh J, Kim KW, Park SJ, Kim HJ, Lee JS, Ha HK, Tirumani SH and Ramaiya NH: Imaging features of primary tumors and metastatic patterns of the extraskeletal Ewing sarcoma family of tumors in adults: A 17-year experience at a single institution. Korean J Radiol 16: 783-790, 2015.

22. Somarouthu BS, Shinagare AB, Rosenthal MH, Tirumani H, Hornick JL, Ramaiya NH and Tirumani SH: Multimodality imaging features, metastatic pattern and clinical outcome in adult extraskeletal Ewing sarcoma: Experience in 26 patients. $\mathrm{Br}$ J Radiol 87: 20140123, 2014.

23. Galyfos G, Karantzikos GA, Kavouras N, Sianou A, Palogos K and Filis K: Extraosseous Ewing sarcoma: Diagnosis, prognosis and optimal management. Indian J Surg 78: 49-53, 2016.

24. Brisse H, Ollivier L, Edeline V, Pacquement $\mathrm{H}$, Michon J, Glorion $\mathrm{C}$ and Neuenschwander S: Imaging of malignant tumours of the long bones in children: Monitoring response to neoadjuvant chemotherapy and preoperative assessment. Pediatr Radiol 34: 595-605, 2004.

25. Gerth HU, Juergens KU, Dirksen U, Gerss J, Schober O and Franzius C: Significant benefit of multimodal imaging: PET/CT compared with PET alone in staging and follow-up of patients with Ewing tumors. J Nucl Med 48: 1932-1939, 2007.

26. Brinkhuis M, Wijnaendts LC, van der Linden JC, van Unnik AJ, Voûte PA, Baak JP and Meijer CJ: Peripheral primitive neuroectodermal tumour and extra-osseous Ewing's sarcoma; a histological, immunohistochemical and DNA flow cytometric study. Virchows Arch 425: 611-616, 1995.

27. Folpe AL (ed.) and Inwards CY: Bone and Soft Tissue Pathology. Saunders, Elsevier, Philadelphia, PA, USA, pp 367-379, 2010.

28. Hornick JL (ed.): Practical soft tissue pathology: A diagnostic approach. Elsevier, Philadelphia, PA, USA, pp 269-297, 2018

29. Downing JR, Head DR, Parham DM, Douglass EC, Hulshof MG Link MP, Motroni TA, Grier HE, Curcio-Brint AM and Shapiro DN: Detection of the $(11 ; 22)(\mathrm{q} 24 ; \mathrm{q} 12)$ translocation of Ewing's sarcoma and peripheral neuroectodermal tumor by reverse transcription polymerase chain reaction. Am J Pathol 143 1294-1300, 1993.
30. Sorensen PH, Lessnick SL, Lopez-Terrada D, Liu XF, Triche TJ and Denny CT: A second Ewing's sarcoma translocation, $\mathrm{t}(21 ; 22)$, fuses the EWS gene to another ETS-family transcription factor, ERG. Nat Genet 6: 146-151, 1994.

31. Biermann JS: Updates in the treatment of bone cancer. J Natl Compr Canc Netw 11 (Suppl 5): S681-S683, 2013.

32. Casali PG, Bielack S, Abecassis N, Aro HT, Bauer S, Biagini R, Bonvalot S, Boukovinas I, Bovee JVMG, Brennan B, et al: Bone sarcomas: ESMO-PaedCan-EURACAN clinical practice guidelines for diagnosis, treatment and follow-up. Ann Oncol 29 (Suppl 4): iv79-iv95, 2018.

33. Covelli HD, Beekman JF and Kingry RL: Extraskeletal Ewing's sarcoma: Prolonged survival with recurrence after operation. South Med J 73: 1294-1295, 1980

34. Rud NP, Reiman HM, Pritchard DJ, Frassica FJ and Smithson WA: Extraosseous Ewing's sarcoma. A study of 42 cases. Cancer 64: $1548-1553,1989$

35. Womer RB, West DC, Krailo MD, Dickman PS, Pawel BR, Grier HE, Marcus K, Sailer S, Healey JH, Dormans JP and Weiss AR: Randomized controlled trial of interval-compressed chemotherapy for the treatment of localized Ewing sarcoma: A report from the children's oncology group. J Clin Oncol 30: 4148-4154, 2012.

36. Donaldson SS: Ewing sarcoma: Radiation dose and target volume. Pediatr Blood Cancer 42: 471-476, 2004

37. Gaspar N, Hawkins DS, Dirksen U, Lewis IJ, Ferrari S, Le Deley MC, Kovar H, Grimer R, Whelan J, Claude L, et al: Ewing sarcoma: Current management and future approaches through collaboration. J Clin Oncol 33: 3036-3046, 2015.

38. Schuck A, Ahrens S, Paulussen M, Kuhlen M, Könemann S, Rübe C, Winkelmann W, Kotz R, Dunst J, Willich N and Jürgens H: Local therapy in localized Ewing tumors: Results of 1058 patients treated in the CESS 81, CESS 86, and EICESS 92 trials. Int J Radiat Oncol Biol Phys 55: 168-177, 2003.

39. Donaldson SS, Torrey M, Link MP, Glicksman A, Gilula L, Laurie F, Manning J, Neff J, Reinus W, Thompson E and Shuster JJ: A multidisciplinary study investigating radiotherapy in Ewing's sarcoma: End results of POG \#8346. Pediatric oncology group. Int J Radiat Oncol Biol Phys 42: 125-135, 1998.

40. Bolling T, Schuck A, Paulussen M, Dirksen U, Ranft A, Könemann S, Dunst J, Willich N and Jürgens H: Whole lung irradiation in patients with exclusively pulmonary metastases of Ewing tumors. Toxicity analysis and treatment results of the EICESS-92 trial. Strahlenther Onkol 184: 193-197, 2008.

41. Takenaka S, Naka N, Obata H, Joyama S, Hamada K, Imura Y, Kakunaga S, Aoki Y, Ueda T, Araki N and Yoshikawa H: Treatment outcomes of Japanese patients with Ewing sarcoma: Differences between skeletal and extraskeletal Ewing sarcoma. Jpn J Clin Oncol 46: 522-528, 2016.

42. Lee JA, Kim DH, Lim JS, Koh JS, Kim MS, Kong CB, Song WS Cho WH, Lee SY and Jeon DG: Soft-tissue Ewing sarcoma in a low-incidence population: Comparison to skeletal Ewing sarcoma for clinical characteristics and treatment outcome. Jpn J Clin Oncol 40: 1060-1067, 2010.

43. Orr WS, Denbo JW, Billups CA, Wu J, Navid F, Rao BN, Davidoff AM and Krasin MJ: Analysis of prognostic factors in extraosseous Ewing sarcoma family of tumors: review of St. Jude children's research hospital experience. Ann Surg Oncol 19: 3816-3822, 2012

44. Biswas B, Shukla NK, Deo SV, Agarwala S, Sharma DN Vishnubhatla S and Bakhshi S: Evaluation of outcome and prognostic factors in extraosseous Ewing sarcoma. Pediatr Blood Cancer 61: 1925-1931, 2014

45. Haeusler J, Ranft A, Boelling T, Gosheger G, Braun-Munzinger G, Vieth V, Burdach S, van den Berg H, Juergens $H$ and Dirksen U: The value of local treatment in patients with primary, disseminated, multifocal Ewing sarcoma (PDMES). Cancer 116: 443-450, 2010

46. Kinsella TJ, Triche TJ, Dickman PS, Costa J, Tepper JE and Glaubiger D: Extraskeletal Ewing's sarcoma: Results of combined modality treatment. J Clin Oncol 1: 489-495, 1983. 